\title{
ACTIVE HEAD SLIDERS USING PIEZOELECTRIC THIN FILMS FOR FLYING-HEIGHT CONTROL
}

\author{
Kenji SUZUKI*, Takayuki AKIMATSU*, Kenji SASAKI ${ }^{*}$ and Masayuki KURITA** \\ * Department of Engineering Synthesis, Faculty of Engineering, The University of Tokyo \\ 7-3-1 Hongo, Bunkyo-ku, Tokyo 113-8656, JAPAN \\ e-mail:suzuki@mech.t.u-tokyo.ac.jp,aki@sdl.t.u-tokyo.ac.jp,sasaki@sdl.t.u-tokyo.ac.jp \\ ** Mechanical Engineering Research Laboratory, Hitachi, Ltd. \\ 502 Kandatsu-cho,Tsuchiura-shi, Ibaraki 300-0013, JAPAN \\ e-mail:kurita@merl.hitach.co.jp
}

\begin{abstract}
This paper describes design and fabrication of a MEMS-based active head slider using a PZT thin film for flying height control in magnetic recording. An air bearing surface (ABS) geometry which generates very low aerodynamic lift force at the head has been designed. The slider has been fabricated monolithically by silicon micromachining process. Change in the flying height of the head above a spinning disk has been successfully confirmed by applying voltage to the PZT actuator.
\end{abstract}

\section{INTRODUCTION}

To achieve high recording densities in hard disk drives, reduction of the head-disk spacing is essential. The spacing of today's hard disk drives is as small as $10 \mathrm{~nm}$ and further reduction of the spacing is difficult because conventional sliders require margin for spacing variation due to manufacturing tolerances and environmental changes. In this study, a novel concept of spacing control using a PZT thin film is proposed to compensate the margin and to keep a constant ultra-low spacing during the read/write operation. An active slider was first developed ten years ago for contact recording ${ }^{[1]}$. Since then, various kinds of sliders with bulk $\mathrm{PZT}^{[2]}$, thin film $\mathrm{PZT}^{[3]}$, and thermal actuators ${ }^{[4]}$ have been reported. However they have not been in practical use.

\section{DESIGN AND NUMERICAL ANALYSIS}

\subsection{Structural design}

A structure of the active head slider is shown in Fig.1. The slider has a standard "pico-slider" size ( 1 by 1.25 by $0.3 \mathrm{~mm}$ ) and a PZT unimorph cantilever with a head at the end is integrated in the central rear part of the slider. The slider was designed to meet following conditions: the displacement of the cantilever is more than $30 \mathrm{~nm}$ and the resonant frequency is more than $100 \mathrm{kHz}$.

\subsection{Air bearing surface (ABS) design}

In order to bring the head close to the disk surface, it is required to reduce the aerodynamic lift force generated under the head. We have designed a new air bearing surface geometry with 5 pads based on the molecular gas film lubrication (MGL) theory ${ }^{[5]}$, as shown in Fig.2. Four pads in each corner of the slider generate sufficient pressure to support the load, while the pad under the head generates little pressure. Variation of the flying heights of the head $h$ and the slider body $h_{0}$ with applied voltage was calculated by coupling MGL and piezoelectric analyses. Figure 3 shows the results of the calculation when the circumferential speed of the disk is $9.61 \mathrm{~m} / \mathrm{s}$ and the load is $26 \mathrm{mN}$. $h$ ' represents the height of the head when the aerodynamic reaction force is neglected. The slider body keeps a constant flying height independent of the head position. Voltage required to change the height of the head from $20 \mathrm{~nm}$ to $5 \mathrm{~nm}$ is calculated as $2.23 \mathrm{~V}$.

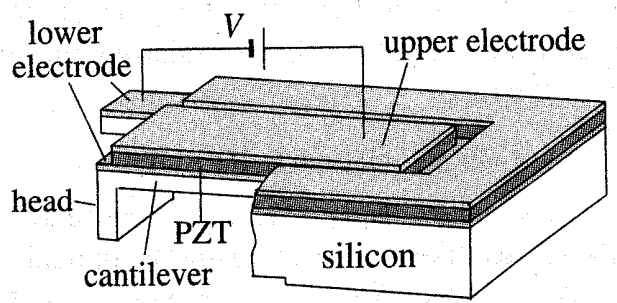

Fig. 1 Schematic of the active head slider

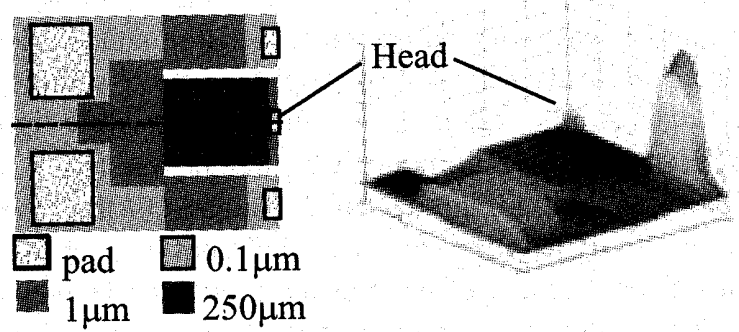

Fig.2 ABS design and pressure distribution.

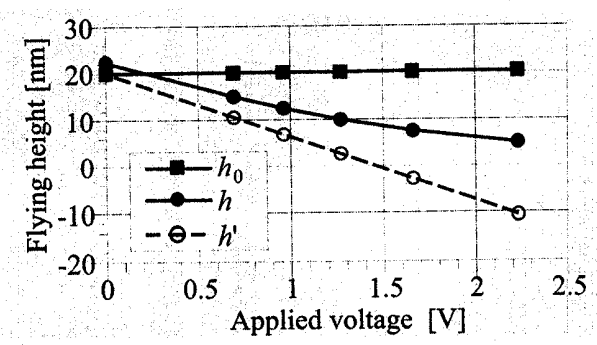

Fig.3 Variation of flying height with applied voltage 

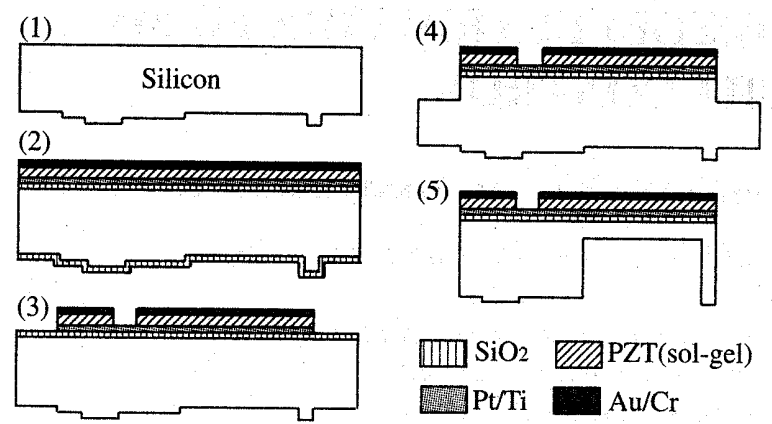

(5)
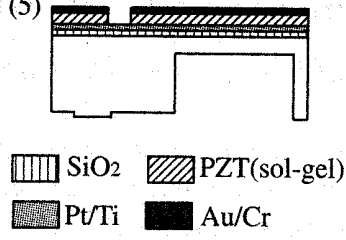

Fig.4 Fabrication process

\section{FABRICATION}

The slider with a PZT unimorph cantilever is fabricated monolithically by silicon micromachining process, as shown in Fig. 4. A $300 \mu$ m-thick silicon wafer is etched from the backside by $\mathrm{KOH}$ solution for patterning ABS. Then an insulating layer ( $\mathrm{SiO} 2)$, a lower electrode $(\mathrm{Pt} / \mathrm{Ti})$, a $2 \mu \mathrm{m}$-thick PZT film, and an upper electrode $(\mathrm{Au} / \mathrm{Cr})$ are deposited sequentially. The PZT layer is coated by sol-gel method. The upper electrode and the PZT film are patterned by ECR (electron cyclotron resonance) etching. Then the upper part of the slider profile is etched by deep-RIE (reactive ion etching). Lastly, the $50 \mu \mathrm{m}$-thick cantilever and the side wall of the slider is formed simultaneously by deep-RIE, and the slider is separated from the wafer. Fig. 5 shows micrographs of the fabricated slider.

\section{TESTING AND RESULTS}

Fig.6 shows the displacement of the end of the $0.55 \mathrm{~mm}$-long cantilever measured by an optical surface profiler. The displacement varies almost linearly with applied voltage up to $5 \mathrm{~V}$. Piezoelectric constant $d_{31}$ was evaluated to be $182 \times 10^{-12} \mathrm{~m} / \mathrm{V}$ by least-squares fitting.

The slider was mounted on the suspension and bonded to electrical leads. The flying height above a spinning glass disk was measured by means of white-light interferometry. The minimum flying height was found to be $30 \mathrm{~nm}$ at the trailing edge of the slider. On the other hand, the flying height of the head could not be measured quantitatively because of warp of the cantilever. However, shift of the interference pattern was observed at the end of the cantilever by changing the applied voltage, as
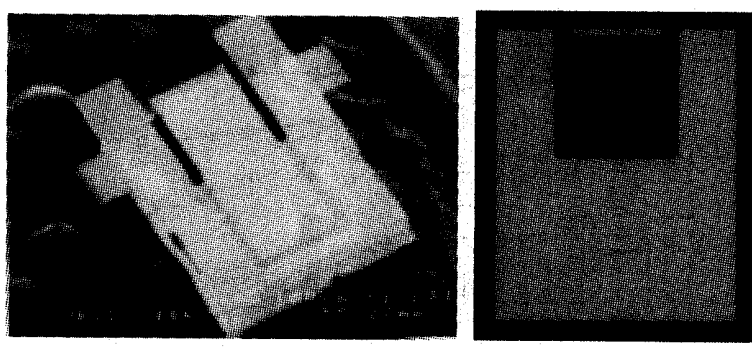

Fig. 5 Micrographs of the slider

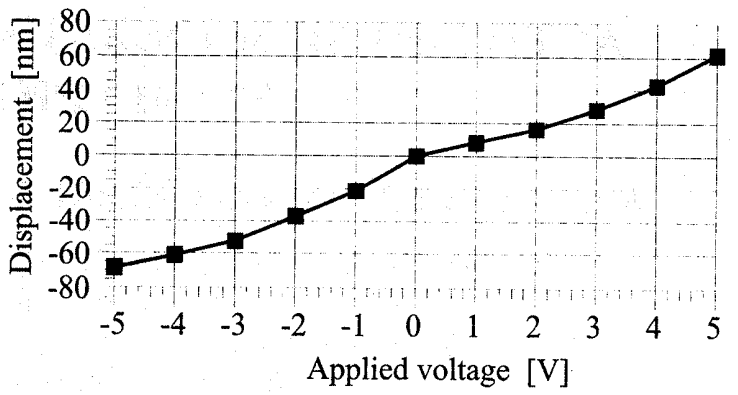

Fig. 6 Displacement of the cantilever tip

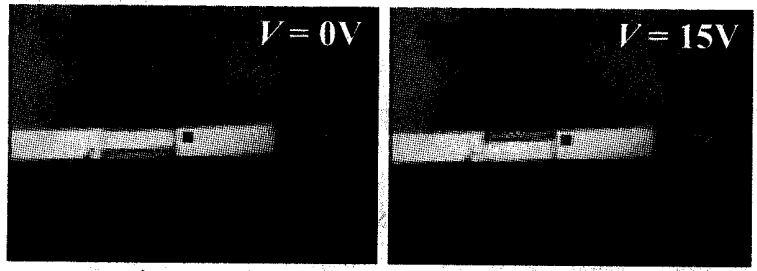

Fig. 7 Shift of the interference pattern

shown in Fig.7. Shaded area in Fig.7 indicates a red interference band. This result demonstrates that the flying height of the head can be controlled using a piezoelectric thin film actuator.

\section{CONCLUSION}

1. A structure of an active head slider using a PZT thin film for flying height control has been designed.

2. An ABS geometry suited for the active head slider, which has 5 pads and generates little aerodynamic force under the head, has been designed based on the MGL theory and the piezoelectric analysis.

3. The slider with a PZT unimorph cantilever has been fabricated monolithically by silicon micromaching process.

4. Vertical displacement of the head was confirmed while the slider was flying above a spinning disk. This result demonstrates the possibility of controlling flying height using a PZT thin film.

\section{REFERENCES}

[1] Yeack-Scranton, C. E., et al., An active slider for practical contact recording, IEEE Trans. Magnetics, Vol.26, No.5, 1990, pp.2478-2483.

[2] Kurita, M. et al., An Active-Head Slider With a Piezoelectric Actuator for Controlling Flying Height, IEEE Trans. Magnetics, Vol.38, No.5, 2002, pp.2102-2104.

[3] Tagawa, N., et al., Design and Fabrication of MEMSBased Active Sliders Using Double-Layered Composite PZT Thin Films in Hard Disk Drives, Digest of the APMRC 2002, 2002, pp. CP4-01-02.

[4] P. Machtle et al., Integrated Microheaters for In-Situ Flying-Height Control of Sliders Used in Hard-Disk Drives, IEEE Proc. MEMS 2001, 2001, pp. 196-199.

[5] Fukui, S. and Kaneko, R., Analysis of Ultra-Thin Gas Film Lubrication Based on Linearized Boltzmann Equation, ASME J.Tribology, Vol. 110, 1988, pp.253-261. 